\title{
RA?EGA
}

O ESPACO GEOGRÁFICO EM ANÁLISE

\section{REDES DE AGROECOLOGIA E PRODUÇÃO ORGÂNICA NA REGIÃO SUL DO BRASIL}

\section{AGROECOLOGY AND ORGANIC PRODUCTION NETWORKS IN SOUTHERN BRAZIL}

\author{
Roberto Antônio Finatto \\ Universidade Federal da Fronteira Sul- UFFS \\ Campus Laranjeiras do Sul, PR, Brasil \\ e-mail: robertofinatto@gmail.com
}

\section{Recebido em: 24/07/2015}

\section{Aceito em: 09/05/2016}

\section{Resumo}

A agroecologia e a produção orgânica vêm se constituindo como alternativas diante dos problemas ambientais, sociais e econômicos gerados pela produção agrícola convencional. Elas, entretanto, possuem particularidades e são praticadas por diferentes atores que ao desenvolverem determinado projeto dão forma àquilo que identificamos como Redes de Agroecologia e Redes de Produção Orgânica. Este artigo analisa as relações nas redes de algumas cooperativas, associações e empresas que desenvolvem a agroecologia e a produção orgânica na região Sul do Brasil. As Redes de Agroecologia são caracterizadas pela predominância de fluxos curtos representando a preferência pelo mercado local e regional para os produtos, pela diversidade de funções ocupada pelos agricultores - além da produção de matéria-prima - e pela predominância da modalidade de certificação participativa. As Redes de Produção Orgânica têm o mercado como elemento determinante na sua configuração, a predominância de fluxos de produtos e a função dos agricultores limitada à esfera da produção.

Palavras-Chave: Rede geográfica; Agricultura; Região Sul (Brasil).

\section{Abstract}

The agroecology and the organic production have been constituting alternatives to the environmental, social and economic problems caused by the conventional agricultural production. However, they have some particularities and are practiced by different actors that while developing some projects, create what we identify as Agroecology Networks and Organic Production Networks. This article examines the relationships in the networks of a number of cooperatives, associations and companies that develop agroecology and organic production in southern Brazil. The Agroecology Networks are 


\section{REDES DE AGROECOLOGIA E PRODUÇÃO ORGÂNICA NA REGIÃO SUL DO BRASIL}

characterized by the predominance of short flows, which represents the preference for local and regional products market, due to the diversity of roles occupied by farmers - in addition to the production of raw materials - and by the predominance of the participatory certification modality. The Organic Production Networks have the market as a determinant element in its configuration, the flow of products predominance and the function of farmers limited to the sphere of production.

Key Words: Geographic network; Agriculture; Southern Brazil.

\section{INTRODUÇÃO}

Os sistemas orgânicos de produção têm potencial de contribuir significativamente para a produção mundial de alimentos (BADGLEY et al., 2007). O mercado mundial de orgânicos avançou a partir da ampliação da área de produção agrícola, que passou de 11 milhões de hectares em 1999 para 37,2 milhões em $2011^{1}$. Dez países no mundo possuem cerca de $70 \%$ da área de agricultura orgânica, sendo que Austrália, Argentina e Estados Unidos possuem as maiores áreas (WILLER e LERNOUD, 2013). O mercado mundial de orgânicos movimentou 62,8 bilhões de dólares em 2011, um crescimento de $170 \%$ em relação a 2002. Entretanto, apenas Europa e América do Norte respondem por $96 \%$ do consumo total desses produtos (SAHOTA, 2013).

No caso do Brasil, de acordo com informações do Cadastro Nacional de Produtores Orgânicos havia, em 2014, 10.064 unidades de produção em sistema orgânico certificadas (envolvendo 6.719 produtores). A produção é diversificada, mas o número de unidades com produção primária vegetal é o mais significativo. A região Sul do país - estados do Rio Grande do Sul, Santa Catarina e Paraná - possuía 3.165 unidades certificadas, ficando apenas atrás da região Nordeste do país (3.198 unidades) ${ }^{2}$.

Os produtos orgânicos têm como característica básica a eliminação de insumos de origem sintética ao longo do seu processo de produção e

\footnotetext{
${ }^{1}$ Dados produzidos pela IFOAM e pelo Research Institute of Organic Agriculture (FIBL) tendo como base as informações do setor privado, certificadoras e governo de cada país.

2 Disponível em Ministério da Agricultura, Pecuária e Abastecimento (MAPA). $<$ http://www.agricultura.gov.br/desenvolvimento-sustentavel/organicos $>$. Acesso em 10 de fevereiro de 2014.
} 


\section{REDES DE AGROECOLOGIA E PRODUÇÃO ORGÂNICA NA REGIÃO SUL DO BRASIL}

processamento; prioriza-se, também, o uso de energias renováveis, de produtos naturais e técnicas que maximizam o efeito positivo de processos biológicos no solo e nas plantas. Para que a produção seja efetivamente considerada orgânica ela deve atender aos princípios legais, como a exclusão dos produtos de uso não permitidos pela legislação vigente. Isso permite ao agricultor utilizar um selo que identifica que determinado produto passou por um processo diferenciado de produção.

Entretanto, além da particularidade de não utilizar produtos químicos, existem outros elementos e relações que também podem ser incorporados a uma agricultura ecológica. É nessa perspectiva que extrapola a unidade de produção onde a agroecologia encontra o seu lugar. Se a produção orgânica representa um avanço no aspecto ambiental, minimizando significativamente as externalidades negativas da atividade agropecuária, é no conjunto de elementos relacionados com a agricultura - ambientais, sociais, culturais, econômicos, políticos, etc. — que a agroecologia vem se projetando.

Dessas características particulares da agroecologia e da produção orgânica, resultam formas diferentes de conceber e de se relacionar com o ambiente e com as pessoas. A geografia, enquanto discurso sobre a ordem espacial do mundo (GOMES, 1997), pode contribuir com o debate das diferentes estratégias e alternativas em curso no espaço rural. Uma das vias para isso se ampara no conceito de rede. Como "a rede representa um dos recortes espaciais possíveis para compreender a organização do espaço contemporâneo" (DIAS, 2005, p.23) buscamos, por meio desse conceito, analisar as relações e estratégias utilizadas por algumas cooperativas, associações e empresas que desenvolvem a produção orgânica e a agroecologia na região Sul do Brasil.

Para tanto, realizamos pesquisa de caráter qualitativo e utilizamos duas técnicas básicas para obtenção dos dados: as entrevistas amparadas em roteiros semiestruturados e o questionário. No total, foram realizadas entrevistas com representantes de seis cooperativas, três associações e oito empresas. Dez dos entrevistados são também agricultores. O questionário foi 
um instrumento que permitiu conhecer melhor os vínculos e a rede formada pela organização da qual o representante entrevistado fazia parte. Sua análise tornou-se mais produtiva diante da disponibilidade das informações das entrevistas. Os exemplos dos questionários, apresentados nas figuras ao longo do artigo, apontam a tendência geral dos resultados da análise e do tipo de rede da qual fazem parte, ou seja, aquilo que identificamos como as Redes de Agroecologia ou Redes de Produção Orgânica.

\section{PRODUÇÃO ORGÂNICA E AGROECOLOGIA}

A agricultura orgânica, atividade básica associada à produção orgânica em sentido mais amplo, teve origem na Inglaterra e tornou-se um movimento organizado a partir da publicação de pesquisas conduzidas na Índia pelo agrônomo inglês Sir Albert Howard. A ideia central nos trabalhos de Howard era a de que "um solo provido de níveis altos de matéria orgânica asseguraria uma vida intensa e rica para a flora microbiana, pela qual a nutrição e a sanidade das plantas seriam plenamente atendidas" (BONILLA, 1992, p.16). $\mathrm{Na}$ agricultura orgânica a fertilidade é potencializada por meio de processos biológicos, uso de biofertilizantes, adubação verde e orgânica, rotação e consorciação de cultivos, entre outras práticas. A ideia central desse sistema de produção é utilizar produtos e processos naturais ao longo da cadeia produtiva, preservando a produtividade dos agroecossistemas.

A principal organização internacional de fomento à produção orgânica é a International Federation of Organic Agriculture Movements (IFOAM), fundada em 1972, na França. Ela congrega certificadoras, organizações de agricultores e demais entidades do setor com o intuito de estimular a produção, apoiar projetos, normatizar e articular o movimento mundial em torno da produção orgânica (IFOAM, 2014). Segundo a definição adotada pela IFOAM (2014), a agricultura orgânica é

um sistema de produção que promove a saúde dos solos, ecossistemas e pessoas. Tem como base os processos ecológicos, biodiversidade e ciclos adaptados às condições locais em alternativa ao uso de insumos com efeitos adversos. A Agricultura orgânica combina a tradição, inovação e ciência de modo a ser benéfica para o espaço partilhado, promove relacionamentos justos assegurando uma boa qualidade de vida a todos os envolvidos. 


\section{REDES DE AGROECOLOGIA E PRODUÇÃO ORGÂNICA NA REGIÃO SUL DO BRASIL}

A definição apresentada é abrangente, uma vez que parte da importância do solo, passa pela valorização da biodiversidade, das pessoas e das especificidades locais para promover aumento da qualidade de vida, sem dispensar a importância do conhecimento científico.

Entretanto, apesar dos esforços na ampliação do seu sentido, podemos afirmar que, cada vez mais, a produção orgânica vem sendo confinada pelas regras e normativas da certificação. A agricultura orgânica da atualidade tem como foco o uso de processos biológicos e insumos orgânicos em detrimento daqueles de origem sintética.

Feiden (2005) recorda que, inicialmente, os agricultores aderiam ao sistema orgânico movidos pela preocupação ambiental ou com sua saúde, entendendo a unidade produtiva como um todo integrado. Entretanto, com a abertura do mercado, muitos agricultores perceberam nesta atividade um negócio e surge uma agricultura orgânica que se sustenta apenas sobre as normas da legislação vigente.

Essa normatização tem conduzido à produção dos "orgânicos por substituição", ou seja, mantém-se o mesmo modelo de produção convencional, substituindo os insumos químicos pelos orgânicos. Como destaca Assis (2005, p.14) "essa (re) interpretação do que seja agricultura orgânica, com foco prioritário no chamado "mercado de produtos orgânicos", tem favorecido o estabelecimento de sistemas de produção tidos como orgânicos, baseados em tecnologias de produtos".

A substituição de insumos embora seja importante em relação à diminuição do impacto ambiental, para a saúde do agricultor e do consumidor, tem efeito limitado, já que mantém o mesmo padrão do sistema convencional. É na busca de uma alternativa a este modelo que a agroecologia vem se projetando. Ela utiliza uma abordagem integrada tanto no interior dos agroecossistemas - sua base de análise - como no contexto socioeconômico onde o mesmo está inserido. Ela pode ser considerada uma ciência e um conjunto de práticas (ALTIERI e TOLEDO, 2011) e/ou uma teoria, uma prática e um movimento social (PLOEG, 2011). 


\section{REDES DE AGROECOLOGIA E PRODUÇÃO ORGÂNICA NA REGIÃO SUL DO BRASIL}

A agricultura familiar camponesa, por sua vez, é considerada como o segmento socioprodutivo que melhor comporta os princípios da agroecologia (CARMO, 2004; ASSIS, 2006; HESPANHOL, 2008). Diante da sua capacidade histórica de resistir aos diferentes constrangimentos econômicos e ecológicos, os camponeses apresentam características compatíveis com a agroecologia (SEVILLA GUZMÁN, 2006; ALTIERI, 2010; ALTIERI e TOLEDO, 2011; PLOEG, 2011).

As características de uma ciência complexa ou multidimensional inerente à agroecologia devem ser também incorporadas na extensão rural. A Nova Extensão Rural, como apontam Caporal e Costabeber (2001, p.05), "deverá orientar-se pela busca contínua de estratégias que impulsionem padrões socioculturalmente desejáveis, apoiados na evolução histórica dos grupos sociais em sua coevolução com o ecossistema em que estão inseridos". Nesse processo, Caporal (2003) destaca a importância dos serviços públicos relacionados à Assistência Técnica e extensão Rural (ATER) para apoiar a transição agroecológica.

A agroecologia se tornará efetivamente viável se os atuais problemas relacionados à produção, distribuição e consumo dos produtos, para além da unidade de produção, também forem solucionados. Gliessman, (2005, p.593) destaca que "é a interação complexa entre todas as dimensões, ecológica, técnica, social e econômica, de nossos sistemas alimentares que determinará se estes podem ser sustentáveis a longo prazo". Nesse sentido, faz parte dos princípios da agroecologia tratar do acesso aos alimentos, uma vez que de nada adiantaria produzir alimentos de forma ecológica se o seu acesso continuasse restrito a um pequeno grupo de consumidores. Esta questão é complexa, pois envolve diretamente as relações entre a unidade de produção, ou seja, um agroecossistema que possui elevada autonomia - se manejado dentro dos princípios da agroecologia - e o mercado convencional, onde o agricultor, via de regra, não tem capacidade direta de controle. Se o agricultor é altamente dependente do mercado, ele acaba sendo obrigado a tomar decisões de acordo com a realidade econômica e não com os princípios 


\section{REDES DE AGROECOLOGIA E PRODUÇÃO ORGÂNICA NA REGIÃO SUL DO BRASIL}

ecológicos (GLIESSMAN, 2005). Gliessman (2005, p.600) aponta, então, que a transição agroecológica deve passar da sustentabilidade dos agroecossistemas para a sustentabilidade dos sistemas alimentares.

Diante do exposto fica claro que não podemos considerar agroecologia e agricultura orgânica como sendo termos sinônimos, apesar de haver algumas similaridades entre os mesmos. Uma característica marcante na agricultura orgânica é a sua dependência às regras dos organismos de certificação. Embora as normas tenham função fundamental na regulação da produção, Primavesi (1997, p.143) aponta que "a agricultura orgânica somente orientada por normas não visa tanto melhorar a condição do agricultor quanto proteger o consumidor do uso indiscriminado e quase criminoso de agrotóxicos". Na agroecologia o consumidor tem a mesma importância que qualquer outro integrante do sistema agroalimentar e não se pode privilegiar o interesse do consumidor ou orientar o sistema agrícola a partir das suas necessidades.

A execução de um projeto de agroecologia e/ou de produção orgânica pelos diferentes atores exige o contato com diferentes instituições, recursos e posicionamentos políticos. Essas ações podem ser, em boa parte, reveladas a partir da abordagem em rede.

\section{ALGUMAS CONSIDERAÇÕES SOBRE O CONCEITO DE REDE}

Schmitt (2011) reconhece que a noção de rede vem sendo empregada por uma diversidade de concepções teóricas, sendo difícil agrupar os trabalhos que dela fazem uso. Mesmo assim, reconhece três principais linhas interpretativas no uso das redes atreladas ao desenvolvimento rural: a perspectiva orientada ao ator, a Teoria do Ator Rede e a análise das redes sociais na perspectiva dos estudiosos da sociologia econômica ${ }^{3}$.

Nossa proposta analítica tem como um dos interlocutores principais a Teoria do Ator-Rede, uma vez que ela fornece elementos que se alinham à

\footnotetext{
${ }^{3}$ A autora também destaca a contribuição dos pesquisadores ligados ao programa Enlarging the Understanding of rural Development in Europe (ETUDE), como Jan Douwe Van der Ploeg, Terry Marsden, Perluigi Milone e Flaminia Ventura. Apesar da aproximação com a perspectiva orientada ao ator nos seus trabalhos, eles também dialogam com outras abordagens sobre as redes.
} 


\section{REDES DE AGROECOLOGIA E PRODUÇÃO ORGÂNICA NA REGIÃO SUL DO BRASIL}

perspectiva geográfica de rede. Latour (2012, p.108) afirma que "[...] qualquer coisa que modifique uma situação fazendo diferença é um ator - ou, caso ainda não tenha figuração, um actante". Ao tratar da teoria em questão Schmitt (2011, p.93) afirma que "o ponto de partida da análise não é a ordem instituída mas, sim, os processos plurais e incompletos através dos quais a ordem é construída". É essa a perspectiva que apresentaremos na sequência deste trabalho, ou seja, como os diferentes atores ao construírem relações entre si produziram redes mais próximas dos princípios da agroecologia ou da produção orgânica.

Santos (2008) destaca que as redes revelam a própria estrutura socioespacial e apresenta a sua dualidade ao considerá-las, simultaneamente, locais e globais, virtuais e reais, técnicas e sociais, concentradoras e dispersoras, estáveis e dinâmicas, unas e múltiplas. As adjetivações ao mesmo tempo em que caracterizam a complexidade dos processos em rede também revelam a versatilidade e maleabilidade do conceito. A análise de Santos apesar da ênfase no papel da intencionalidade com que as redes são produzidas, enfatiza o aspecto material das mesmas. Essa ideia, entretanto, pode ser entendida de forma mais ampla.

Uma contribuição nesse sentido foi feita por Latour (2012) - a quem o próprio Santos faz referência. Latour destaca o papel dos híbridos (humanos e não humanos) e situa as associações entre os diferentes atores como elemento base de constituição do social. Teríamos, assim, um conjunto de associações de durabilidades diversas que ao se produzirem irão também produzindo a própria sociedade.

Entretanto, é igualmente necessário reconhecer que como qualquer mecanismo de apreensão do real, a rede não permite abranger a totalidade das associações existentes entre os atores. Há, assim, elementos que extrapolam os espaços das conexões. Latour (2012, p.347) propõe o termo plasma para caracterizar "aquilo que ainda não foi formatado, medido, socializado, inserido em cadeias metrológicas, coberto, vistoriado, mobilizado, subjetificado". O plasma é, portanto, muito mais amplo do que aquilo que está sendo medido ou 


\section{REDES DE AGROECOLOGIA E PRODUÇÃO ORGÂNICA NA REGIÃO SUL DO BRASIL}

vistoriado. Essa consideração ao mesmo tempo em que reconhece os limites da análise, ressalta que a complexidade do social não pode ser apreendida por uma análise espacial e temporalmente datada.

A perspectiva de Latour (2012) aproxima-se com a abordagem da geografia, uma vez que ao trazer os objetos na teia das associações que, em determinado momento, são produzidas para configurar uma rede, permite dar visibilidade aos elementos materiais, úteis na abordagem da rede geográfica.

A rede geográfica enquanto parte fundamental da espacialidade humana pode ser considerada um caso particular de rede, sendo definida por Corrêa (2012, p.200) como "o conjunto de localizações humanas articuladas entre si por meio de vias e fluxos". O principal fato destacado pela geografia está atrelado à localização, à espacialização dos fluxos no espaço geográfico e à seleção dos lugares onde ocorrem as conexões. Cabe destacar que esses lugares não foram escolhidos ao acaso, mas por possuírem as características necessárias ao desenvolvimento das distintas redes.

Por permitir a circulação e a comunicação, a rede é uma representação do poder (RAFFESTIN, 1993). É oportuno lembrar que os objetos também portam informação (SANTOS, 2008). A materialização desse processo pode ser exemplificada na produção orgânica e agroecológica. Ao mesmo tempo em que ocorre a circulação dos produtos também há a transferência de informação imbuída nos próprios produtos em circulação. Sem esse elemento imaterial o conhecimento associado aos produtos - a circulação não ocorreria. A informação relacionada aos produtos e processos de produção orgânicos também é um elemento transferido entre os atores que compõem a rede. Ocorre, neste caso, uma relação dialética entre o fluxo imaterial e material já que um depende do outro para se efetivar.

O componente geográfico independe do conteúdo da rede. Se, por um lado, as modernas redes técnicas, baseadas no avanço da ciência e da tecnologia ganharam destaque nas últimas décadas, é também importante reconhecer o impacto de redes mais localizadas que, embora possam estar imbuídas de menor carga tecnológica, também se constituem como 


\section{REDES DE AGROECOLOGIA E PRODUÇÃO ORGÂNICA NA REGIÃO SUL DO BRASIL}

estratégicas para os atores que delas fazem parte. Nesse sentido, o alcance das conexões exige uma discussão da finalidade da rede, que nem sempre está materialmente demarcada.

Há, aqui, um componente essencial para as diferentes redes: a política da escala ${ }^{4}$. Como recorda Smith (2000, p.157) "ao estabelecer fronteiras, a escala pode ser construída como um meio de restrição e exclusão, como um meio de impor identidade. Mas uma política da escala pode se tornar também uma arma de expansão e inclusão, um meio de ampliar as identidades".

Assumimos a premissa de que a política de escala exige, em certo sentido, um conjunto de alianças que envolve a mobilização em rede. Ao discutir sobre 0 alcance das interações sociais e 0 dinamismo do comportamento dos atores ao mobilizarem elementos do "micro" ao "macro", Latour (2012, p.267) afirma que "a escala é a própria realização do ator" e que ela "[...] é o que os atores realizam representando escalando, espaçando e contextualizando uns aos outros mediante o transporte em alguns veículos específicos de alguns traços específicos" (p.266). Swyngedouw (2004, p.33) também defende que as escalas devem ser consideradas como um processo, por isso "spatial scales are never fixed, but are perpetually redefined, contested and restructured in terms of their extent, content, relative importance and interrelations". A redefinição das escalas revela a necessidade constante que os atores possuem de criar novas alianças em diferentes níveis para a manutenção do projeto defendido.

Independente das formas com que a escala é utilizada — seja como um produto real, concreto, resultado dos processos sociais ou como matriz teórica preexistente para ordenar processos e práticas da vida social (HEROD, 2003) - ela deve ser considerada a partir da leitura do fenômeno em uma perspectiva relacional. É oportuno identificar o alcance das redes com base no

\footnotetext{
${ }^{4}$ Souza (2010, p.42 apud Souza 2013, p. 196) define a política de escala como "a articulação de ações e agentes operando em níveis escalares diferentes (isto é, que possuem magnitudes e alcances distintos) com a finalidade de potencializar efeitos, neutralizar ou diminuir o impacto de ações adversas ou tirar maiores vantagens de situações favoráveis; por exemplo, ampliando esferas de influência (ao expandir audiências, sensibilizar atores que sejam possíveis aliados etc.) e propiciando sinergias políticas (ao recrutar novos apoios, costurar alianças etc.)".
} 


\section{REDES DE AGROECOLOGIA E PRODUÇÃO ORGÂNICA NA REGIÃO SUL DO BRASIL}

movimento de expansão mediado pelas estratégias internas e pelos constrangimentos impostos pelos mecanismos reguladores externos.

Finalmente, por se constituírem vias de ligação e permitirem o movimento de diferentes tipos de fluxos as redes envolvem relações de poder. A construção de relações pode ocorrer via alinhamento ao modelo hegemônico ou pela produção de alternativas via geração de estratégias adequadas àqueles não (ou parcialmente) integrados à lógica dominante. A seguir, destacaremos como essas diferentes posturas se manifestam nas Redes de Agroecologia e nas Redes de Produção Orgânica.

\section{REDES DE AGROECOLOGIA E REDES DE PRODUÇÃo ORGÂNICA: OS ELEMENTOS CLASSIFICATÓRIOS}

Os elementos diferenciadores destacados a seguir além de se constituírem como característicos de um ou outro sistema ${ }^{5}$ - produção orgânica e agroecologia - são traços comuns identificados durante a pesquisa de campo. Desde já, ressaltamos que não identificamos modelos puros. Com base na análise das entrevistas e dos questionários aplicados rastreamos traços específicos e comuns entre os atores. Acreditamos que esse respaldo empírico corrobore a apresentação dos diferentes tipos de rede.

A classificação dos atores foi orquestrada a partir dos seguintes princípios: (1) a ideia de pertencimento à agroecologia ou à produção orgânica: identificada a partir do discurso dos entrevistados e da rede de vínculos mantida pela organização da qual fazem parte; (2) o papel dos agricultores: se apenas fornecedores da matéria-prima (produtos orgânicos in natura) ou se participam diretamente de processos decisórios e influenciam nos rumos da organização com a qual mantém relação comercial; (3) as relações com o mercado : se há predomínio de relações com o mercado convencional e, não raro, o fato de produzir orgânicos para atender a um nicho de mercado após uma análise das carências do mesmo ou se ocorre a construção de canais de comercialização alternativos e a preferência por canais de maior

\footnotetext{
${ }^{5}$ Em alguns trechos nos referimos à agroecologia como um sistema de produção ou tipo de agricultura. Essa consideração, em hipótese alguma, minimiza o seu significado já exposto.
} 
proximidade entre agricultor e consumidor; (4) posicionamento político em relação aos mecanismos de controle: a aceitação ampla dos mecanismos de controle ou se há interesse em aperfeiçoar esses mecanismos ajustando-os às características da produção; (5) modalidade de certificação empregada: se há a preferência pela certificação participativa ou pela certificação por auditoria externa (isso não significa que ambas não possam estar presentes); (6) predominância de relações verticais ou horizontais na gestão: se o projeto desenvolvido visa a autonomia dos agricultores, sendo que eles participam das diferentes etapas do processo (da gestão à produção da matéria-prima) ou se ocorre uma relação mais vertical na gestão dos empreendimentos, incluindo o uso de trabalho assalariado como elemento essencial para a realização das atividades; (7) espacialidade da rede: se há predominância de relações voltados para o município ou a região ou se há o predomínio de relações que extrapolam esse limite regional ${ }^{6}$; (8) número e diversidade dos vínculos: se ocorre a predominância de fluxo de produtos (de matéria-prima e de produtos processados) e financeiro ou se há maior diversidade de relações que abrangem ainda os fluxos de informações (no esforço de elaborar políticas públicas e formas democráticas de acesso aos produtos).

Essa classificação não tem a finalidade de apontar um ou outro modelo como um tipo ideal, mas procura evidenciar a existência de diferenças importantes entre os dois tipos de rede. A seguir qualificaremos os critérios expostos e apresentaremos as redes identificadas.

\subsection{As características e as relações das Redes de Produção Orgânica}

Quando questionados sobre as motivações para desenvolver a produção orgânica alguns dos entrevistados apontaram razões de, basicamente, duas naturezas que em alguma medida confluíram: o interesse particular e uma oportunidade de mercado. O mercado representa, nesse caso, a via que

\footnotetext{
${ }^{6}$ Essa característica é particularmente importante pelo aumento da demanda energética para o deslocamento dos produtos. Atrelado a isso, quando exportados, nos casos analisados, esses produtos acabam sendo destinados a consumidores de maior poder aquisitivo, restringindo 0 acesso aos mesmos. Isso não significa que nas Redes de Agroecologia não possa existir exportação de produtos ou a existência de fluxos longos.
} 


\section{REDES DE AGROECOLOGIA E PRODUÇÃO ORGÂNICA NA REGIÃO SUL DO BRASIL}

possibilita a expansão dos benefícios da produção orgânica para as demais pessoas. Esse posicionamento fica evidente nas seguintes afirmações: "nós somos consumidores de orgânicos há muitos anos, então é uma coisa que veio de casa, um hábito nosso. [...] e nós ${ }^{7}$ tivemos a ideia de começar a trabalhar alimentação orgânica. A gente detectou uma carência nesse mercado" (ENTREVISTADO 01, 2013). O entrevistado 02 (2013) ainda acrescenta: "é uma ideologia nossa que a gente tem dessa consciência do meio ambiente, de cuidar do meio ambiente e também pelo apelo financeiro que tem, o apelo de venda, é um atrativo, digamos assim, para o consumidor".

Um dos elementos que motivou o desenvolvimento da produção foi a observação do mercado, sobretudo na Europa e Estados Unidos, onde há maior oferta de produtos orgânicos. Os entrevistados assim manifestam essa questão: "a gente trouxe da Europa esse conceito que lá é muito forte, fiquei maravilhada com a variedade de produtos que tem lá" (ENTREVISTADO 03, 2013), ou, ainda, "desde o começo, observando os produtos na gôndola a gente viu que faltava e vendo a oportunidade no crescimento de orgânicos, como já tinha feito a plantação, então a gente começou a adaptar pra trabalhar com o sistema orgânico" (ENTREVISTADO 04, 2013).

O apelo comercial da produção orgânica é evidenciado nos mais variados produtos, ficando claro que o mercado teve um papel importante na definição do tipo de produto a ser comercializado. Ao ser questionado sobre os motivos para trabalhar com a apicultura orgânica um entrevistado afirma que "primeiro existe uma demanda de mercado bastante grande, segundo a nossa apicultura comparada com a apicultura de outros países exportadores de mel é bastante primitiva e, por ser primitiva, tinha que fazer poucos ajustes para tornar orgânica" (ENTREVISTADO 05, 2013).

As falas dos entrevistados referem-se a uma gama diversificada de produtos, como o mel, palmito, sucos, geleias, comida pronta congelada e cosméticos. Mesmo que essas iniciativas de produção orgânica devam sua origem a uma necessidade particular, o mercado foi um elemento fundamental

\footnotetext{
7 Os trechos em itálico em meio às citações diretas referem-se às alterações feitas para preservar a identidade do entrevistado ou da empresa da qual faz parte.
} 


\section{REDES DE AGROECOLOGIA E PRODUÇÃO ORGÂNICA NA REGIÃO SUL DO BRASIL}

para que a ideia se materializasse em áreas de produção e indústrias de processamento. Não raro, o desenvolvimento de um produto de elevado valor agregado revela o interesse de atingir um nicho de mercado.

Uma característica fundamental das Redes de Produção Orgânica é que os agricultores têm como função específica o fornecimento de matéria-prima, já que nem todas as empresas possuem área de produção própria. Por isso, como pode ser observado nas figuras 01 e 02, o fluxo de matéria-prima, caracterizado sobretudo por produtos in natura, é um dos principais componentes dessas redes.

A figura 01 apresenta os principais fluxos de uma empresa que trabalha com a produção de néctar de frutas, geleias, polpa de tomate, farinha de trigo e achocolatado. A origem da matéria-prima é diversificada, mas se concentra na região Sul do país. Destaque para São Paulo como fonte de matéria-prima quando algum produto não pode ser encontrado na região citada.

Nessa mesma lógica a empresa $\mathrm{A} 2^{8}$ (figura 02) que produz comida pronta congelada (purês, sopa, espaguete e risoto), embora tenha sua rede de fornecedores de matéria-prima mais próximos, também mantém relação com São Paulo para a compra de carne de frango orgânica certificada, produto que só nos últimos dois anos passou a ser produzido no sul do país. $\mathrm{O}$ apoio dado pelo fornecedor da carne ao projeto da empresa, entretanto, ainda mantém esse vínculo com São Paulo. A origem da matéria-prima no município sede da empresa, não apresentada na figura, refere-se principalmente à compra de produtos orgânicos nas feiras-livres do município.

O tempo de existência das duas diferentes redes apresentadas é um fator que contribui decisivamente para a intensidade dos fluxos e número de vínculos. Enquanto a empresa A1 é da década de 1990, a empresa A2 foi criada em 2011. Nesse sentido, a rede da empresa A2 provavelmente sofrerá

\footnotetext{
${ }^{8}$ Alguns representantes de empresas de produtos orgânicos solicitaram que o nome da mesma não fosse divulgado. Com o objetivo de atender a essa solicitação e padronizar a redação identificamos as empresas com letras e números. No caso das demais empresas, associações e cooperativas não apresentadas nas figuras, quando citadas no texto, apenas fazemos referência a alguma de suas características para que o leitor possa conhecer o contexto em que a informação apresentada foi produzida.
} 


\section{REDES DE AGROECOLOGIA E PRODUÇÃO ORGÂNICA NA REGIÃO SUL DO BRASIL}

mudanças mais significativas nos próximos anos, tendendo a uma expansão maior do que a primeira. Isso foi constatado, inclusive, durante a pesquisa de campo. Às informações coletadas em 2013 foram acrescentados novos dados em 2014. Assim, foi possível aproximar a representação da realidade da empresa por meio da inserção dos vínculos surgidos no período.

A posição ocupada pelos agricultores nas Redes de Produção Orgânica - exclusivamente como fornecedores de matéria-prima - é importante, pois reproduz uma relação típica do sistema de produção convencional. Em certos casos ocorre um processo muito similar ao modelo de integração, onde a empresa fornece a assessoria e o material necessário para o desenvolvimento da produção a fim de garantir que sua demanda de matéria-prima esteja assegurada. Um dos entrevistados, cuja empresa comercializa frutas e hortaliças tais como agrião, alface, rúcula, cenoura e outros, destaca a importância dos agricultores integrados para a manutenção da regularidade dos produtos comercializados pela sua empresa: "a gente difundiu essa ideia e hoje nós temos 43 produtores integrados. Além da nossa produção própria a gente tem outros produtores familiares que produzem pra gente. Então faz três anos que a gente contratou um agrônomo que dá assistência" (ENTREVISTADO 06, 2013). 
FINATTO, R. A.

REDES DE AGROECOLOGIA E PRODUÇÃO ORGÂNICA NA REGIÃO SUL DO BRASIL

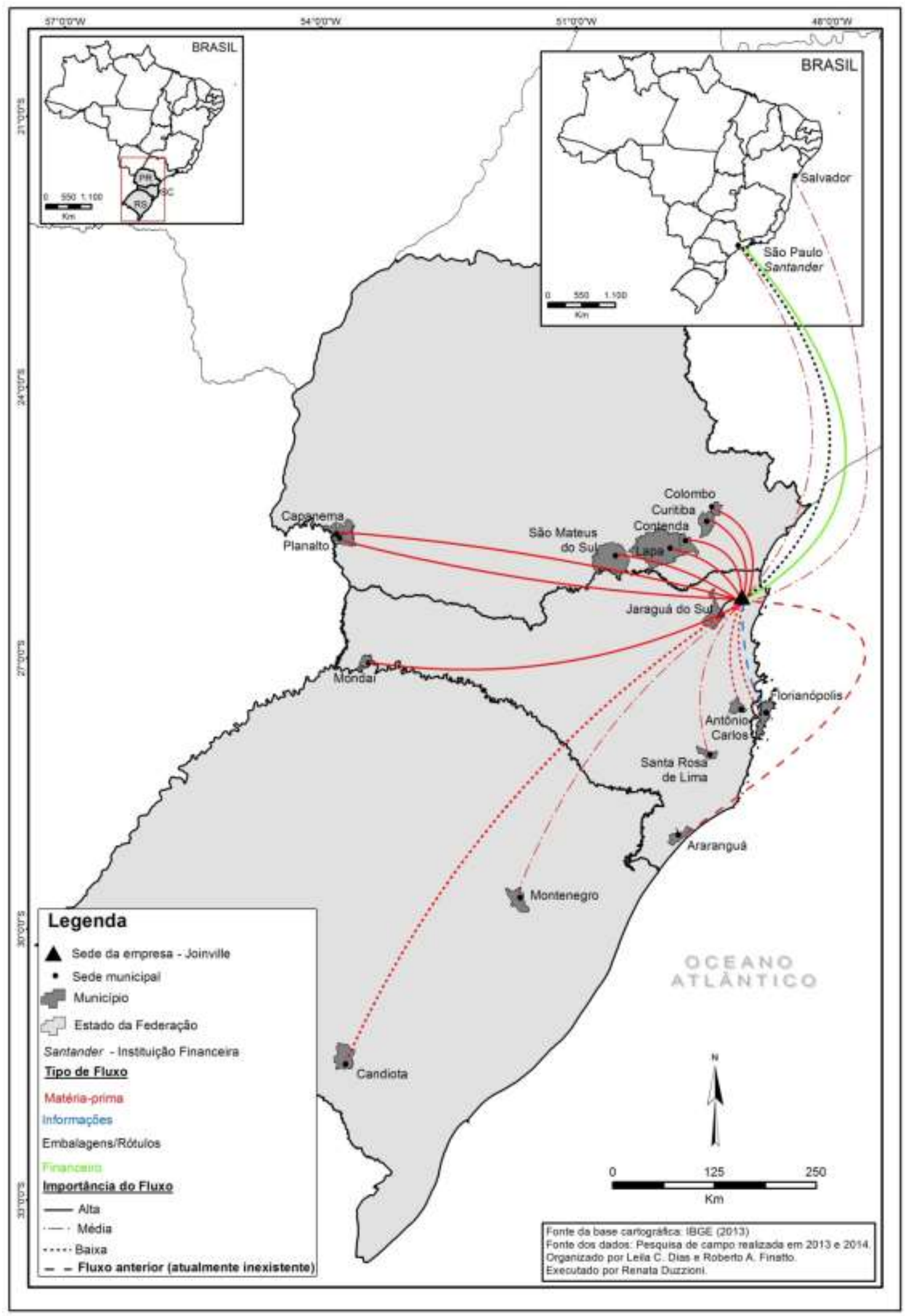

Figura 01: Rede de Produção Orgânica da empresa A1, 2014

R. Ra'e Ga - Curitiba, v. 38, p. 107 - 145 , Dez./2016 
FINATTO, R. A.

REDES DE AGROECOLOGIA E PRODUÇÃO ORGÂNICA NA REGIÃO SUL DO BRASIL

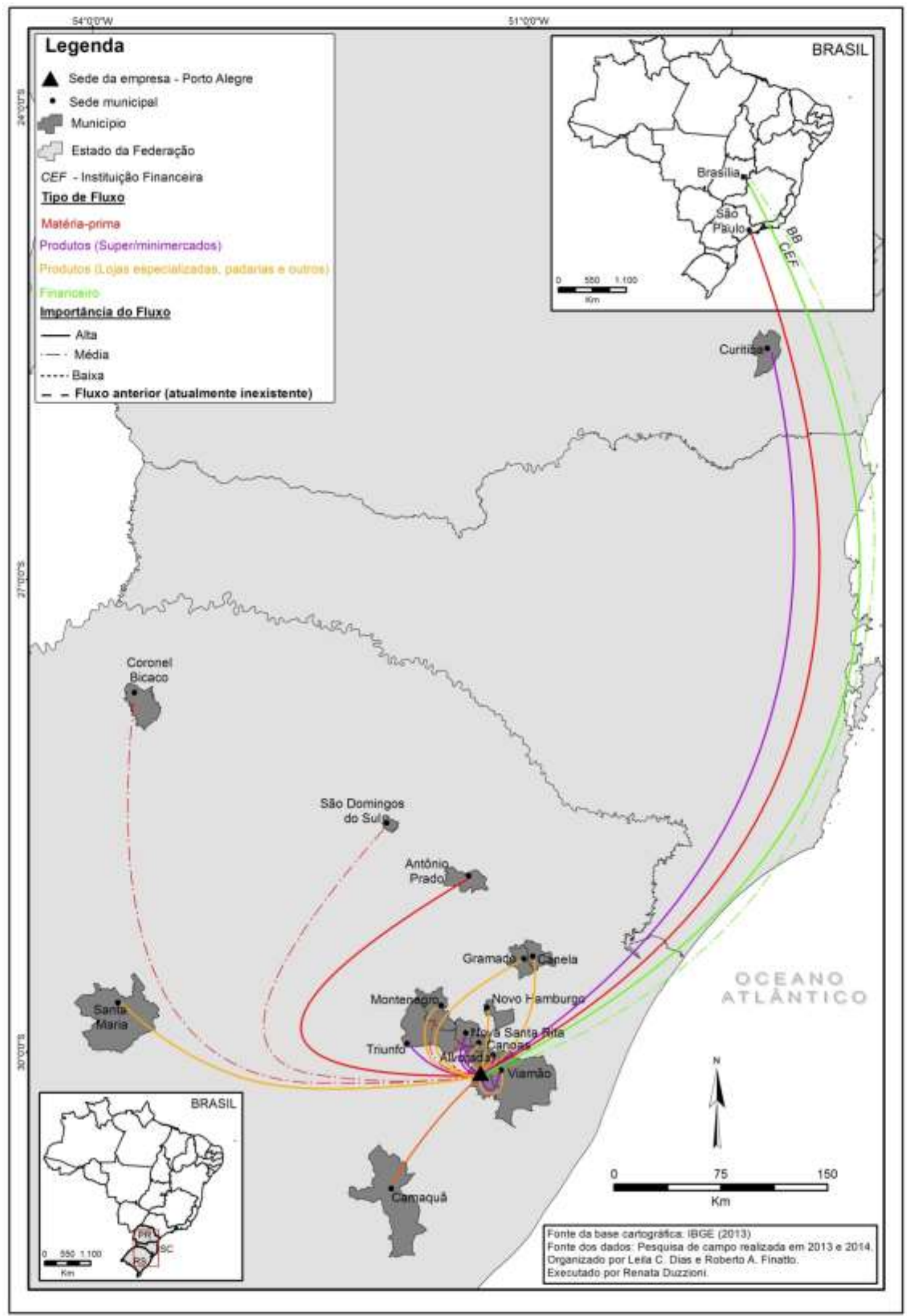

Figura 02: Rede de Produção Orgânica da empresa A2, 2014

R. Ra'e Ga - Curitiba, v. 38, p. 107 - 145 , Dez./2016 


\section{REDES DE AGROECOLOGIA E PRODUÇÃO ORGÂNICA NA REGIÃO SUL DO BRASIL}

Como destacado por outro empresário do setor, eles próprios motivaram os apicultores a entrarem no projeto orgânico. Ele afirma: "a gente já tinha um contato com eles e apresentou a apicultura orgânica, apresentou as exigências que vieram para a apicultura orgânica, se eles tinham como atender e motivou eles a entrarem no projeto" (ENTREVISTADO 05, 2013). O entrevistado 07 (2013) destaca que "a gente incentiva os produtores a plantar para a gente ter os nossos insumos".

Diante da existência dessa relação comercial regida por contratos entre as empresas e os agricultores, o agricultor está sujeito à quebra de contrato se não cumprir com as exigências nele estabelecidas. Há, assim, um nível de qualidade mínimo considerado para os produtos. Visando assegurar esse nível de qualidade satisfatória, o entrevistado 06 (2013) afirma: "a gente passou a dar assistência [técnica] porque a gente não trabalha com qualquer produto". A assessoria técnica também é um recurso utilizado pela empresa A1. A empresa passou a fornecer assessoria para os agricultores que destinam uma quantidade mínima de produção para a mesma.

Se atender ao mercado é um dos objetivos principais dos atores envolvidos com a produção orgânica, a comercialização dos produtos é realizada por meio de dois principais canais de comercialização: os supermercados e as lojas especializadas. Como pode ser visualizado na rede de comercialização da empresa de produção orgânica A1 (figura 03) e A2 (figura 02) os vínculos com esses canais de comercialização são importantes e fundamentais para as empresas, representados por uma importância alta. Em relação à empresa $\mathrm{A} 2$, a espacialidade da sua rede com a predominância de fluxos localizados no estado da sede deve-se à recente fundação da mesma, ou seja, ela ainda encontra-se em processo de expansão, como já apontado.

Apesar de o fluxo de produtos para os supermercados ainda ter uma importância alta para a empresa $A 1$, a representante da mesma afirma que a relação com esse canal de comercialização já foi mais forte, representando cerca de $80 \%$ das vendas. Para diminuir essa elevada dependência e os riscos 
FINATTO, R. A.

REDES DE AGROECOLOGIA E PRODUÇÃO ORGÂNICA NA REGIÃO SUL DO BRASIL

econômicos associados, a empresa buscou diversificar os canais de comercialização, como mostra a figura 03.

R. Ra'e Ga - Curitiba, v. 38, p. 107 - 145 , Dez./2016 
FINATTO, R. A.

REDES DE AGROECOLOGIA E PRODUÇÃO ORGÂNICA NA REGIÃO SUL DO BRASIL

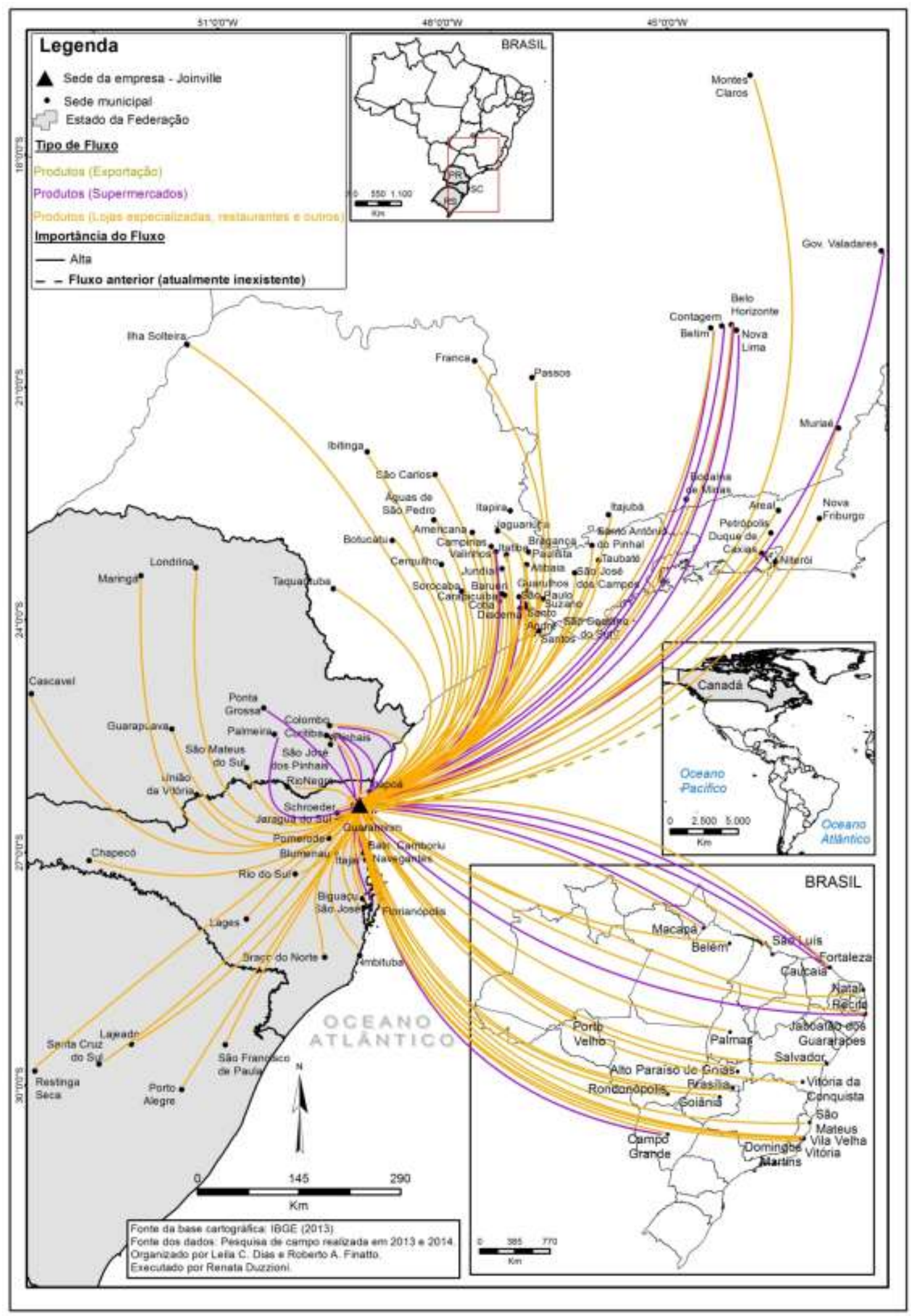

Figura 03: Rede de comercialização dos produtos orgânicos da empresa A1, 2014.

R. Ra'e Ga - Curitiba, v. 38, p. 107 - 145 , Dez./2016 


\section{REDES DE AGROECOLOGIA E PRODUÇÃO ORGÂNICA NA REGIÃO SUL DO BRASIL}

Outra empresa participante da pesquisa que comercializa frutas e hortaliças tais como agrião, alface, cenoura e outros, também tem forte dependência com os supermercados, sendo este o seu principal canal de comercialização. O entrevistado 06 (2013) reconhece as exigências específicas dos supermercados, mas tende a naturalizá-las: "eles dizem [os agricultores com dificuldades de manter relações comerciais com os supermercados]: ah o mercado tá exigindo coisa demais. Mas uma coisa é o seguinte, se o mercado viesse na tua propriedade recolher o produto era uma coisa, agora tu indo lá entregar tu tá acessando, tu tem que se adequar".

O interesse em exportar a produção também aparece como um item importante na organização das Redes de Produção Orgânica. Entretanto, o crescente e amplo mercado interno no país tem constituído o foco principal da maior parte das empresas participantes da pesquisa. Como apresentado na figura 03, a empresa A1 já trabalhou com exportação, mas atualmente está voltada para o atendimento do mercado interno. A exceção no grupo analisado é a empresa de mel orgânico, que trabalha exclusivamente com exportação.

A existência de fluxos longos é uma das principais características dessas redes. $\mathrm{O}$ alcance dos fluxos de produtos tende a ser mais longo do que aqueles das Redes de Agroecologia - como será visto a seguir. Por isso, os fluxos que ocorrem no interior dos municípios-sede das empresas tendem a se restringir aos produtos, sobretudo aos processados. Embora existentes, os fluxos nos municípios não são fundamentais para a manutenção das empresas na atividade, visto que eles são compensados por aqueles mais longos ${ }^{9}$.

O fluxo de informação é bastante pontual e tende a ocorrer nos primeiros meses/anos do empreendimento. Neste momento é quando ocorre a necessidade de informações para orientar questões técnicas e de certificação relacionadas ao cultivo e processamento dos orgânicos, ou mesmo ao gerenciamento da empresa. Outra característica dessas redes é a modalidade

\footnotetext{
${ }^{9}$ Os fluxos que ocorrem no interior dos municípios-sede, não representados nas figuras, se referem, tanto no caso da empresa A1 quanto A2, aos fluxos de produtos (lojas especializadas, restaurantes e outros), de matéria-prima (compra de produtos) e de informações (suporte técnico para a produção/processamento de orgânicos ou relacionada à normatização da atividade).
} 
de certificação utilizada: todas as empresas utilizam a modalidade de certificação por auditoria externa, quando uma empresa é contratada para efetuar a certificação. Alguns agricultores que fornecem a matéria-prima para as empresas utilizam a modalidade de certificação participativa ${ }^{10}$.

A última característica a ser destacada entre os integrantes das Redes de Produção Orgânica é a posição em relação à certificação. Em geral, os representantes das organizações que compõem essas redes consideram os mecanismos de controle como um importante e desejável regulador da atividade. Para o entrevistado 01 (2013) "as mudanças na legislação influenciaram para melhor, ficou um pouco mais rígido, porque logo que começamos qualquer um botava o orgânico. Agora com a legislação ficou uma coisa mais rígida e eu acho melhor". A certificação se configura como o mecanismo regulatório que permite, assim, estruturar o mercado da produção orgânica. Para estes atores, quanto mais rígida a legislação, maior o controle sobre os produtos e processos.

As Redes de Produção Orgânica compartilham intencionalidades e relações que revelam o interesse imediato em atender o mercado consumidor. Disso resulta um arranjo dos fluxos que tem seu alcance moldado por relações comerciais. Muitos dos atores que compõem essas redes são também parte do mercado de produtos convencionais - desde os fluxos de produtos até os financeiros (figuras 01 e 02). Não há, portanto, um interesse em criar estratégias que buscam dar suporte a um projeto alternativo, como o que encontramos nas Redes de Agroecologia.

\subsection{As características e as relações das Redes de Agroecologia}

As Redes de Agroecologia são assim definidas, pois apresentam maior proximidade com as questões teóricas que balizam a agroecologia. Convém

\footnotetext{
${ }^{10}$ Ao contrário da certificação por auditoria externa, na certificação participativa a vistoria nas áreas de produção, agroindústria e outros é realizada por um Conselho de Ética formado por agricultores, técnicos e outros atores diretamente envolvidos com o sistema de produção. Esta modalidade possui custos menores e foi regulamentada pelo Decreto ํㅜ 6.323, de 27 de Dezembro de 2007. A certificação participativa não tem reconhecimento internacional, não sendo válida para casos de exportação.
} 


\section{REDES DE AGROECOLOGIA E PRODUÇÃO ORGÂNICA NA REGIÃO SUL DO BRASIL}

destacar que a agroecologia se construiu teoricamente amparada em diversos exemplos empíricos, sobretudo da América Latina e África. Por isso, há uma intrínseca e dialética relação entre a teoria e a prática agroecológica.

A partir dos critérios classificatórios elencados anteriormente apresentaremos as intencionalidades e relações que marcam as Redes de Agroecologia. Teremos como base, seis exemplos que compartilham os mesmos princípios gerais. A cooperativa escolhida para a representação da rede desse grupo deveu-se à maior disponibilidade de informações sobre a mesma e por ela condensar as principais relações que marcam as Redes de Agroecologia.

A primeira característica desse grupo de atores (agricultores, cooperativas, associações e uma empresa) é a busca de geração de autonomia por meio da produção agroecológica. Para tanto, há um conjunto de ações coletivas desencadeadas em contextos sociais e econômicos mais homogêneos. Nesse caso, ao contrário das Redes de Produção Orgânica, há um interesse em manter o controle em todas as etapas da cadeia produtiva de determinado produto e não prestar um serviço pontual em uma das etapas do processo $^{11}$. A gestão dos empreendimentos é realizada pelos próprios agricultores que acabam acumulando diferentes funções, ou seja, um mesmo agricultor também pode ser representante de associação ou cooperativa.

Há um interesse explícito no discurso de alguns dos entrevistados das Redes de Agroecologia em não se caracterizar como um empreendimento típico capitalista. Isso ocorre via diferentes estratégias utilizadas para manter o controle da atividade e um distanciamento das regras de mercado. O tamanho das organizações, como as cooperativas e as associações, é um dos critérios a ser levado em conta, ou seja, quanto maior o empreendimento - número de associados, volume de produtos e capital mobilizado - menor seria a capacidade dos próprios agricultores decidirem sobre os seus rumos, abrindo espaço para que as regras do mercado conduzam o processo. O entrevistado

11 Embora seja importante reconhecer que podem ocorrer casos em que agricultores vinculados às Redes de Agroecologia também comercializem parte de sua produção para empresas de produção orgânica. 


\section{REDES DE AGROECOLOGIA E PRODUÇÃO ORGÂNICA NA REGIÃO SUL DO BRASIL}

08 (2013) destaca: "a gente sempre defendeu a formação de outros grupos, não tanto concentrar, a nossa visão mais assim não tão capitalista de querer explorar. [...] Também a gente não quer criar um "monstro" onde os agricultores perdem o domínio, o controle".

O interesse em se distanciar do modelo convencional, altamente integrado ao mercado, é também resultado das experiências anteriores dos agricultores. Muitos deles ingressaram na agroecologia porque a produção convencional não se adequava à sua realidade social e econômica. O elevado investimento no pacote tecnológico mantinha os agricultores dependentes de financiamentos que nem sempre eram possíveis de serem quitados com a comercialização da produção. Havia, assim, uma descapitalização contínua. Outro motivo importante que contribuiu para a entrada na agroecologia foram os problemas de saúde resultantes do contato com os agrotóxicos do sistema convencional. Os entrevistados também atribuem sua entrada na agroecologia por causa da preocupação com o consumidor final. A agroecologia também possibilita a agregação de valor à produção. Por isso, é inegável a importância e o apelo econômico atrelado aos produtos oriundos desse sistema de produção. Mesmo que esse não seja o motivo principal de adesão à prática agroecológica, ele é importante uma vez que a atividade deve permitir a reprodução socioeconômica das famílias que a praticam.

Apesar de reconhecerem a importância da legislação e dos regulamentos, os entrevistados possuem um discurso crítico em relação aos mesmos. Para eles, a legislação dificulta o avanço da agroecologia em alguns aspectos na medida em que não controla o sistema de produção convencional (sobretudo o uso de sementes transgênicas e de agrotóxicos). Essa reclamação é exemplificada no fato de que quem arca com os custos da construção de barreiras para isolar a área de produção agroecológica daquelas de produção convencional no entorno da unidade de produção são os agricultores agroecológicos. Nos casos de áreas pequenas isoladas em meio às terras cultivadas no modelo convencional, a construção dessas barreiras obrigatórias por lei para não ocorrer a contaminação da lavoura em sistema 


\section{REDES DE AGROECOLOGIA E PRODUÇÃO ORGÂNICA NA REGIÃO SUL DO BRASIL}

orgânico com os produtos químicos - acaba inviabilizando o desenvolvimento da produção.

Em relação à certificação dos produtos, os atores das Redes de Agroecologia têm preferência pela modalidade participativa. Quando essa não é a modalidade adotada, as cooperativas e associações podem se responsabilizar pelas despesas relacionadas com a mesma ou os agricultores podem criar estratégias para diminuir os custos do processo. Mesmo entre os atores parte dessas redes há o reconhecimento de que o selo da certificadora (via modalidade de certificação por auditoria) tem um reconhecimento maior no mercado. Entretanto, é unânime que os custos da certificação por auditoria são elevados para os agricultores familiares. O entrevistado 09 (2013), representante de uma cooperativa que produz arroz, destaca que "esse tipo de certificação por auditoria é caríssimo, essa questão aí que é um ponto negativo, é que ela custa muito pra nós". O entrevistado 08 (2013), que faz parte da Rede Ecovida de Agroecologia ${ }^{12}$, destaca dois motivos para a preferência pela certificação participativa: "por acreditar que ele é um sistema que dá quase mais credibilidade e outra também por uma redução de custos".

Os três principais canais de comercialização integrantes das Redes de Agroecologia são: as feiras-livres, o mercado institucional e os supermercados.

Um dos principais entraves relacionados à comercialização nas Redes de Agroecologia, sobretudo nos casos de produção de hortaliças e frutas, é a exigência de diversidade e padronização de produtos. Como se sabe, a agroecologia privilegia o cultivo de produtos que melhor se desenvolvem de acordo com as características edafoclimáticas e culturais dos diferentes lugares. Nesse sentido, uma única região, diante das suas particularidades de clima, solo, cultura alimentar e outros elementos, nem sempre pode oferecer a diversidade exigida pelo mercado.

Uma alternativa para conjugar os interesses do mercado, dos consumidores e as diferentes condições geográficas, no âmbito da Rede

12 A Rede Ecovida de Agroecologia foi fundada em 1998 e reúne grupos de agricultores, associações, cooperativas, ONGs, cooperativas de consumidores entre outras entidades do sul do Brasil. 


\section{REDES DE AGROECOLOGIA E PRODUÇÃO ORGÂNICA NA REGIÃO SUL DO BRASIL}

Ecovida de Agroecologia foi criar um fluxo de produtos entre as organizações de diferentes áreas do sul do país. Esse processo foi facilitado pela já existente articulação entre as diferentes organizações que compõem a Rede. Somado a isso, a existência da certificação participativa entre os integrantes da mesma, permite oferecer um produto com o respaldo que o mercado exige. 0 entrevistado 10 (2013) destaca essas relações de cooperação: "a gente chegou num ponto e o que a gente percebeu? Ou a gente se unia nessa questão da comercialização e criava essas rotas ou a gente nunca iria atender mercado nenhum". As rotas citadas pelo entrevistado integram o circuito de comercialização da Rede Ecovida ${ }^{13}$. Esse circuito tem como finalidade aumentar a diversidade de produtos disponíveis contribuindo para a abertura de diferentes canais de comercialização.

Uma característica das cooperativas e associações que constituem as Redes de Agroecologia é a preferência por diversificar os canais de comercialização. Em geral, há preferência pelos canais curtos de comercialização em mercados que compreendem a dinâmica particular de produção da agricultura familiar. Isso permite maior controle por parte das organizações dos agricultores. Nos casos em que o mercado convencional é acessado, ele não é suficientemente forte para moldar a dinâmica de trabalho das diferentes organizações. Entre os integrantes da Rede Ecovida os esforços empenhados na construção de mecanismos alternativos de mercado (PEREZCASSARINO e FERREIRA, 2013) como as feiras-livres, entregas à domicílio e vendas no varejo local se constituem exemplos das estratégias de diversificação na comercialização dos produtos.

\footnotetext{
${ }^{13}$ Como destacado por Magnanti (2008), para integrar o circuito é necessário que os alimentos sejam produzidos de forma ecológica, por agricultores familiares e possuam a certificação participativa da Rede Ecovida. Para otimizar a logística do transporte as organizações que compram os produtos também devem vender algum produto para as outras organizações do circuito. Isso permite que os caminhões responsáveis pelo transporte estejam sempre carregando produtos ao longo do circuito e a menor circulação de dinheiro, já que pode ocorrer a simples troca de produtos, sendo o dinheiro utilizado para cobrir eventuais diferenças de transação entre as cooperativas.
} 


\section{REDES DE AGROECOLOGIA E PRODUÇÃO ORGÂNICA NA REGIÃO SUL DO BRASIL}

A comercialização com as grandes redes de supermercados, via de regra, não constitui o principal mercado acessado por esse grupo, embora possa ocorrer ${ }^{14}$.

Entretanto, em relação aos nós relacionados com a comercialização das Redes de Agroecologia tratadas na pesquisa, o principal destaque é o mercado instituciona $I^{15}$. A rede da cooperativa B1, localizada em Lages/SC, apresenta a importância da produção e do comércio local e regional para a agroecologia ${ }^{16}$ (figura 04).

A importância crescente do mercado local/regional nos últimos anos só foi possível pela existência do mercado institucional, sobretudo do Programa de Aquisição de Alimentos. A cooperativa comercializa quase 1 milhão e meio de reais/ano para esse mercado, representando aproximadamente o destino de $90 \%$ da produção de seus associados. Os principais produtos comercializados são as frutas, verduras e legumes. A preferência por esse mercado deve-se a basicamente dois fatores: problemas com 0 mercado atacadista $e$ as facilidades de operacionalização do mercado institucional. Como apresentado na figura 05, já ocorreu relação com o mercado atacadista de São Paulo e Rio de Janeiro. A experiência não foi exitosa porque esse mercado exigia

\footnotetext{
${ }^{14}$ Uma exceção foi identificada durante a pesquisa de campo. No caso de uma associação, os supermercados das cidades próximas constituem o principal local de comercialização dos produtos. Essa proximidade com o supermercado deve-se ao histórico da organização, uma vez que uma rede de supermercados buscou a associação para iniciar o cultivo ecológico, financiando inclusive algumas máquinas para o processamento. A associação, que trabalha com a comercialização de hortaliças, é composta por 10 famílias, sendo duas delas proprietárias da empresa e dos equipamentos existentes. A criação da empresa deveu-se, ainda, à necessidade de não sobrecarregar a nota dos produtores rurais. Como, em geral, os supermercados só cadastram um fornecedor, os demais agricultores acabam entregando sua produção no nome do produtor cadastrado. Com isso, este agricultor acabaria ficando com rendimentos anuais acima dos $R \$ 128.308,50$ - Limite da renda bruta obtida por pessoa física para a isenção da declaração do Imposto de Renda no ano de 2014 - tendo que, obrigatoriamente, realizar a declaração de Imposto de Renda. Assim, a associação utiliza tanto - CNPJ da empresa, quanto o CPF dos associados para a comercialização, dependendo do volume de produção a ser comercializado para um supermercado específico.

${ }^{15} \mathrm{O}$ mercado institucional refere-se ao Programa de Aquisição de Alimentos (PAA) e ao Programa Nacional de Alimentação Escolar (PNAE).

${ }^{16} \mathrm{~A}$ origem e direção dos fluxos de produtos apresentados na figura 04 não possuem uma correspondência direta com a realidade. Eles apenas servem para representar a circulação dos produtos em nível municipal e regional típica das Redes de Agroecologia. No caso das feiras ecológicas, apresentadas da figura, os agricultores são responsáveis pela organização das mesmas, a cooperativa somente presta uma espécie de assessoria, contribuindo para a maior oferta de produtos via rotas de comercialização da Rede Ecovida.
} 


\section{REDES DE AGROECOLOGIA E PRODUÇÃO ORGÂNICA NA REGIÃO SUL DO BRASIL}

diversidade na oferta e padronização dos produtos, homogêneos em relação ao tamanho e aparência. Como a produção não atendia essa exigência, acabava ocorrendo muito descarte. Além disso, ocorreram casos de inadimplência ou de excessiva demora para o pagamento.

Outra vantagem do mercado institucional, como aponta o entrevistado 10 (2013) é que os agricultores "podem entregar no próprio município, eles podem dialogar com os beneficiários [aqueles que recebem os produtos] os dias de entrega, tem flexibilidade [...], está mais para aquilo que eles podem oferecer de trabalho e produzir". Essa dinâmica pode ser constatada na representação da rede da cooperativa B1 (figura 04), uma vez que ela promove maior número de fluxos no interior ou entre os municípios próximos. 
FINATTO, R. A.

REDES DE AGROECOLOGIA E PRODUÇÃO ORGÂNICA NA REGIÃO SUL DO BRASIL

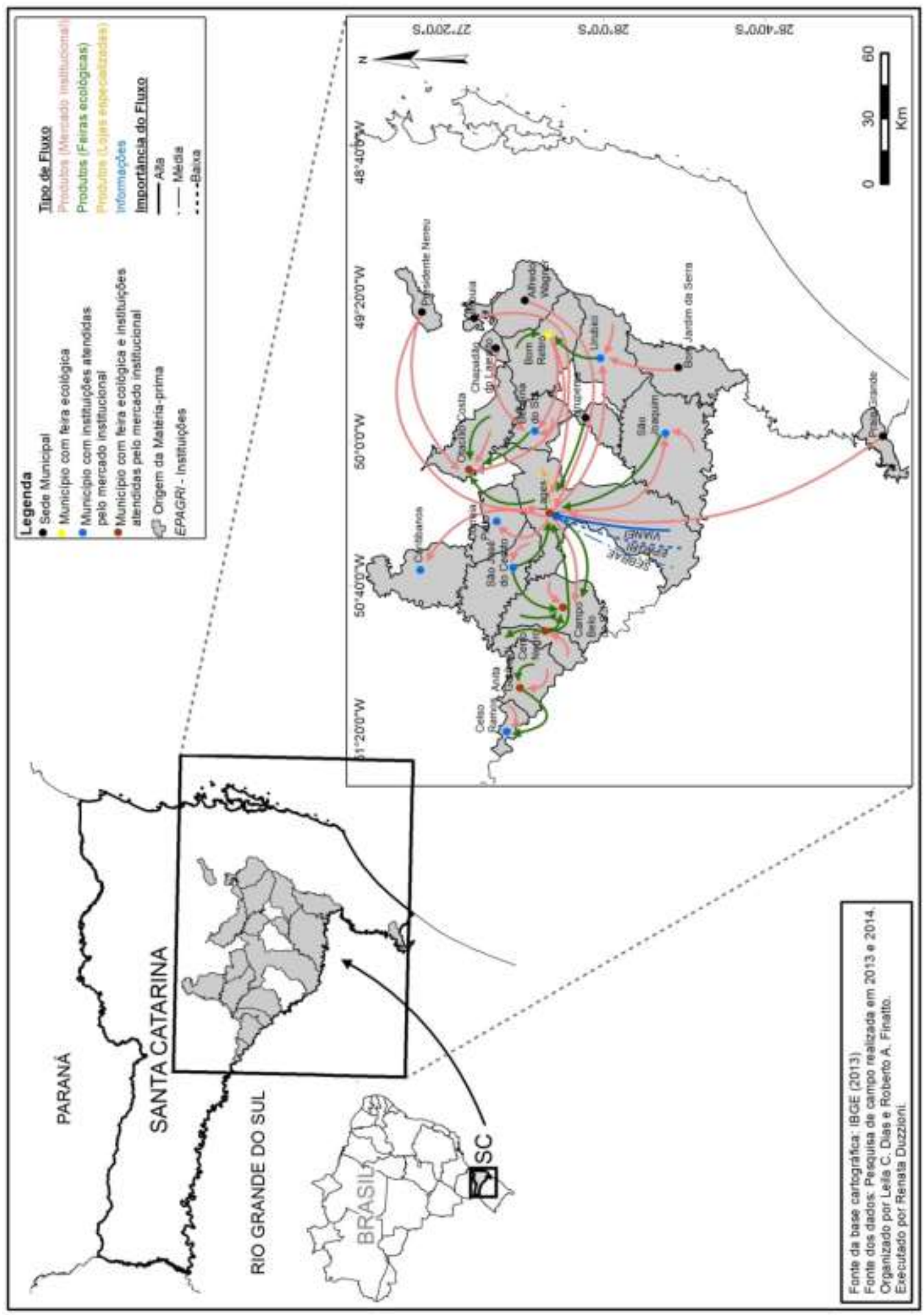

Figura 04: Rede de comercialização da produção agroecológica da cooperativa B1, 2014.

O mérito do mercado institucional é que ele democratiza o acesso aos produtos agroecológicos permitindo que pessoas que talvez não tivessem 


\section{REDES DE AGROECOLOGIA E PRODUÇÃO ORGÂNICA NA REGIÃO SUL DO BRASIL}

condições financeiras para comprar os produtos no mercado convencional, possam também consumi-los. Outra vantagem desse mercado é a facilidade, garantia e rapidez no pagamento pela produção comercializada. Assim, ele se constitui uma alternativa às grandes redes varejistas. O entrevistado 10 (2013) também detalha essa questão: "ao longo dos anos percebemos que ainda não estamos preparados para esse mercado exigente como é esse mercado de fora [...]". A "falta de preparo" citada pelo entrevistado é, em parte, resultado da insuficiente assessoria técnica disponível. Ele acrescenta: "a gente não consegue ainda ter uma assessoria técnica efetiva de campo, constante, infelizmente sai caro [...]". No caso das cooperativas, associações e grupos informais é comum maior proximidade com as $\mathrm{ONGs}^{17}$ (como apresentado na rede da Cooperativa B1, figura 05). As ONGs atuam diretamente com os agricultores sendo responsáveis pela assessoria técnica na produção.

Em relação às empresas e lojas especializadas para a venda de insumos para a produção, as Redes de Agroecologia não apresentam nós importantes em sua configuração. Isso ocorre por dois motivos: primeiro, porque os insumos disponíveis no mercado podem ser encontrados em lojas de produtos agrícolas convencionais; segundo, porque há o interesse e a preferência pela elaboração dos insumos necessários ao desenvolvimento dos diferentes cultivos no interior da unidade de produção, com os recursos ali disponíveis.

\footnotetext{
${ }^{17}$ As Organizações não governamentais tiveram uma atuação fundamental no estímulo inicial aos grupos de agricultura alternativa, ainda na década de 1980, na região Sul do país. Atualmente essas ONGs (CAPA, CETAP, C. ECOLÓGICO, ASSESOAR, CEPAGRO, RURECO, APACO, VIANEI) ainda desenvolvem vários projetos que contemplam a agroecologia. Elas também são membros importantes da já citada Rede Ecovida de Agroecologia e participam diretamente na estruturação da certificação participativa.
} 
FINATTO, R. A.

REDES DE AGROECOLOGIA E PRODUÇÃO ORGÂNICA NA REGIÃO SUL DO BRASIL

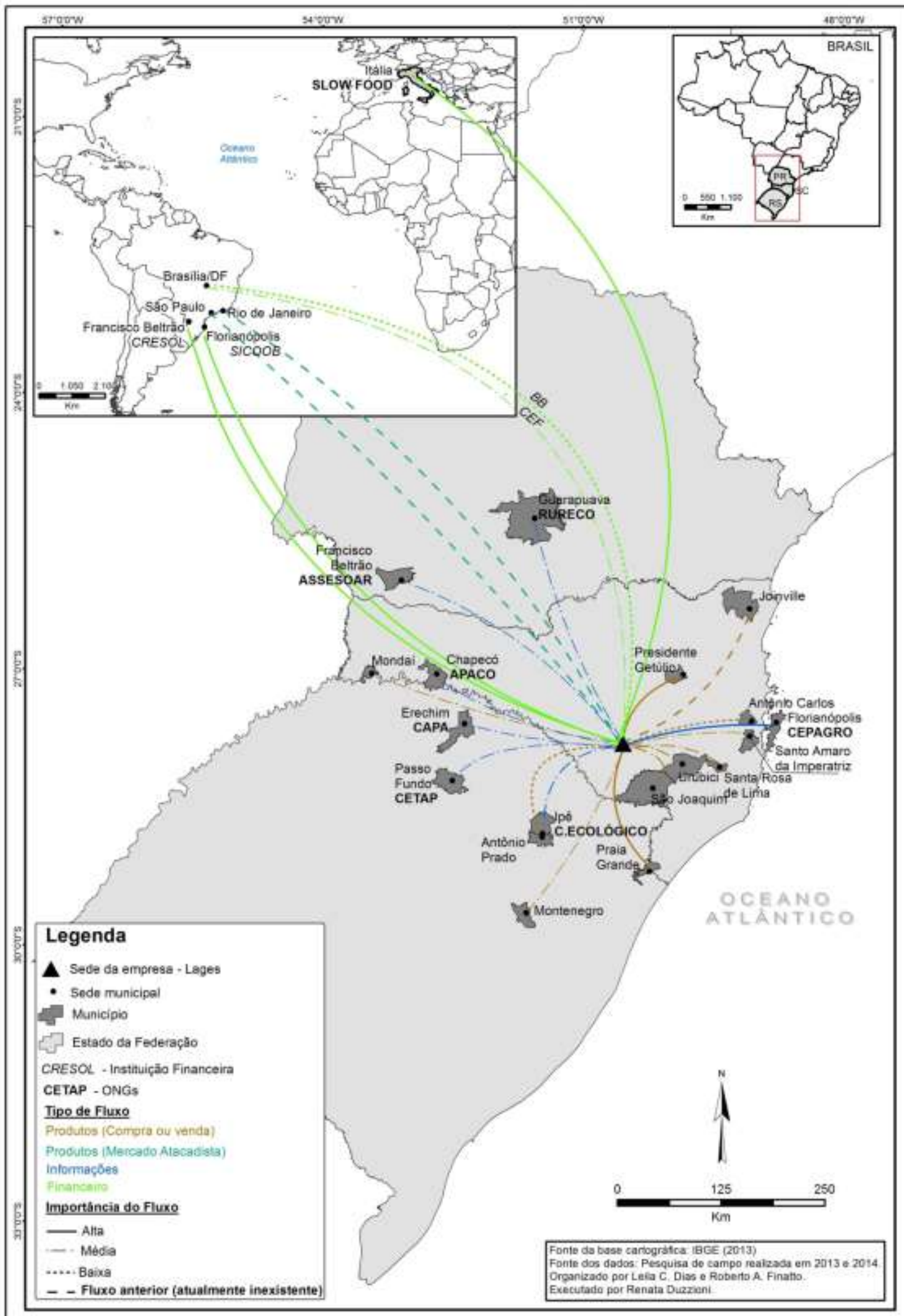

Figura 05: Rede de Agroecologia da cooperativa B1, 2014

R. Ra'e Ga - Curitiba, v. 38, p. 107 - 145 , Dez./2016 


\section{REDES DE AGROECOLOGIA E PRODUÇÃO ORGÂNICA NA REGIÃO SUL DO BRASIL}

As atividades financeiras das Redes de Agroecologia também apresentam particularidades. Como na região Sul do país já existem sólidas instituições de crédito solidário - caso do Sistema Cresol de Cooperativas de Crédito Rural com Interação Solidária e da Cooperativa de Crédito Rural Horizontes Novos de Novo Sarandi Ltda. (Crehnor) - muitos agricultores que trabalham com agroecologia procuram essas instituições para acessar financiamentos e desenvolver suas atividades financeiras. As cooperativas de crédito solidário no meio rural buscam ser úteis ao seu público-alvo, geralmente agricultores familiares de baixa e média renda (FREITAS e FREITAS, 2011). Mesmo enfrentando desafios, essas instituições têm contribuído para democratizar o acesso ao crédito, inserindo parte daqueles agricultores que estiveram historicamente marginalizados das políticas públicas e instituições financeiras tradicionais no Brasil (BÚRIGO, 2006; FREITAS e FREITAS, 2011).

Os agricultores reconhecem as particularidades desses sistemas financeiros. O entrevistado 11 (2013) afirma que "hoje nós trabalhamos mais com a Cresol Cooperativa de Crédito, a gente tem um trabalho melhor, é mais colocado para o pequeno agricultor, a linguagem é mais parecida". Entretanto, a elevada capacidade financeira e o papel desempenhado pelo Banco do Brasil na disponibilização do crédito agrícola ainda coloca essa instituição como sendo o principal nó financeiro das Redes de Agroecologia. O destaque é o Programa Nacional de Fortalecimento da Agricultura Familiar (PRONAF) acessado por meio dessa instituição financeira ${ }^{18}$.

Apesar das particularidades identificadas nos diferentes tipos de rede que reforçam as assimetrias anteriormente apresentadas entre a produção orgânica e a agroecologia, também reconhecemos uma série de pontos de contato entre as mesmas. Alguns deles serão brevemente apresentados na sequência.

\footnotetext{
18 Outros programas também são acessados. Como exemplos, destacamos o Terra Sol cujo principal foco é o fomento à agroindustrialização e à comercialização da produção em assentamentos da reforma agrária; o Empréstimo do Governo Federal (EGF) que propicia o capital de giro para as cooperativas comprarem e estocarem a produção dos associados e o BNDES PSI para a aquisição de máquinas e equipamentos.
} 


\section{OS PROJETOS EM DESENVOLVIMENTO: UMA AÇÃO ARTICULADA?}

Além dos vínculos apresentados também identificamos um conjunto de relações ou vínculos que definimos como assimétricos. Estes vínculos são aqueles que permitem a comunicação entre os diferentes sistemas de produção ou tipos de rede. São assimétricos porque não compartilham de um mesmo projeto, como defendido ao longo do artigo.

Esses vínculos, no âmbito da presente pesquisa, podem ser exemplificados nos casos em que uma associação de agricultores constituída em torno dos princípios da agroecologia - tem como principal canal de comercialização os supermercados que, em geral, não se constituem como um mercado que amplia o acesso aos produtos agroecológicos. Outro exemplo de vínculo assimétrico também ocorre quando uma cooperativa, por apresentar dificuldades de comercializar sua produção para um supermercado, acaba vendendo parte da mesma para uma empresa de produtos orgânicos, que também funciona como uma espécie de intermediário; de posse dessa produção comprada da cooperativa, acrescida de sua própria, a empresa tem as condições necessárias para comercializar para o supermercado.

Os vínculos assimétricos podem variar de muito importantes (como no caso da associação com o supermercado) para pouco importantes (como no caso da cooperativa com a empresa de produção orgânica). Sua existência pode revelar contradições nos diferentes grupos, interesse em maximizar os lucros ou estratégias de resistência frente às imposições de determinado período. Eles resultam de processos particulares construídos historicamente ao longo da existência das diferentes organizações e podem ser transitórios ou permanentes. Esses vínculos se constituem como estratégicos para a manutenção na atividade já que eles solucionarão alguma necessidade específica (comercialização, assessoria técnica e outros). Entretanto, deve-se reconhecer que essas relações também podem produzir incertezas e conflitos 


\section{REDES DE AGROECOLOGIA E PRODUÇÃO ORGÂNICA NA REGIÃO SUL DO BRASIL}

em relação à postura política dos atores envolvidos, já que mesclam interesses diferentes.

É importante destacar que essas redes não se produzem no vazio, mas são/estão altamente integradas a lógicas e relações mais amplas que visam atender diferentes interesses. No que toca à agroecologia, as redes locais ao se fundirem com os movimentos agrários internacionais em favor da soberania alimentar geram uma pressão social capaz de produzir ações políticas que contribuam no seu próprio desenvolvimento (HOLT-GIMÉNEZ e ALTIERI, 2013). Exemplos das articulações entre essas instituições podem ser identificadas entre organizações como a Rede Ecovida de Agroecologia, articulada à Associação Brasileira de Agroecologia (ABA) e à Articulação Nacional de Agroecologia (ANA) e com organizações internacionais como a Sociedad Científica Latinoamericana de Agroecología (SOCLA). Há articulações em diferentes níveis que viabilizam ações planejadas.

\section{CONSIDERAÇÕES FINAIS}

Concluímos que, o que caracteriza se o sistema de produção adotado está mais próximo de um projeto de agricultura orgânica ou da agroecologia não é o tamanho do empreendimento ou a sua figura jurídica (cooperativa, empresa ou associação), mas as intencionalidades e o conjunto de ações resultantes das mesmas. Se, por um lado, as redes tem seus nós localizados sobretudo na região Sul do Brasil, não podemos desconsiderar as relações mais longas que moldam e de certa forma também contribuem para a existência das ações mais localizadas.

Em linhas gerais, as Redes de Produção Orgânica têm como característica básica a verticalidade das relações. Nessas redes, os agricultores são atores fundamentais, já que produzem as matérias-primas, mas, ao mesmo tempo, têm sua atuação limitada à esfera da produção. Como apresentado em alguns exemplos, as empresas prestam assessoria ao agricultor e fornecem as condições para que ele desenvolva a produção a fim de garantir sua demanda de matéria-prima. Nas Redes de Produção Orgânica 


\section{REDES DE AGROECOLOGIA E PRODUÇÃO ORGÂNICA NA REGIÃO SUL DO BRASIL}

a predominância dos fluxos de produtos/materiais - matéria-prima, produtos processados, embalagens, rótulos e outros — revela a ênfase comercial dos projetos. Quando presentes, os fluxos de informações referem-se à assessoria técnica para viabilizar um determinado processo no empreendimento ou na produção.

As Redes de Agroecologia possuem em comum o fato de terem surgido apoiadas na necessidade de criar alternativas técnicas adequadas às características dos agricultores familiares camponeses. A existência das Redes de Agroecologia só foi possível a partir da mobilização e pressão política que permitiram que as alavancas necessárias à constituição desse perfil de redes pudessem se constituir - a legalidade da certificação participativa e a ampliação de produtos ecológicos oriundos da agricultura familiar em programas como o PAA e o PNAE, são exemplos dessas conquistas. As Redes de Agroecologia se forjam, assim, a partir de iniciativas incluídas na ideia de agroecologia política (CALLE COLLADO, et al. 2013). São articulações e dinâmicas socioespaciais formadas a partir de práticas de mudança social que incluem o nível micro (agricultor/agroecossistema) e alcançam um nível macro, tanto no ambiente institucional como em espaços de alianças políticas, científicas e técnicas internacionais. Os principais nós típicos dessas redes identificados na pesquisa são, além dos agricultores, o mercado institucional (ou seja, as instituições beneficiadas pelo PAA e PNAE), as ONGs e as instituições financeiras representadas pelo cooperativismo de crédito solidário.

Ao ressaltarmos as particularidades das redes analisadas $e$ as características que as situam mais próximas de um ou de outro sistema de produção, não pretendemos apresentá-las como redes homogêneas, isentas de contradições, conflitos e rupturas. Uma análise detalhada de casos específicos desses exemplos certamente revelará outros aspectos não apresentados ao longo deste trabalho, diante do percurso teórico e metodológico aqui adotado. As Redes de Agroecologia e as Redes de Produção Orgânica enquanto resultado de um processo social, dinâmico e contínuo, estão constantemente se reajustando, construindo novos vínculos e 
abandonando outros que, em última análise, poderão resultar em projetos cada vez mais híbridos. Certamente outros arranjos socioespaciais poderão ser identificados e problematizados em pesquisas futuras corroborando ou refutando as relações aqui apresentadas.

\section{AGRADECIMENTOS}

O autor agradece o Programa de Pós-Graduação em Geografia da Universidade Federal de Santa Catarina pelo auxílio na pesquisa de campo e a Coordenação de Aperfeiçoamento de Pessoal de Nível Superior (CAPES) pela bolsa de doutorado no Brasil e de doutorado Sanduíche, na Espanha.

\section{REFERÊNCIAS}

ALTIERI, M. Agroecologia, agricultura camponesa e soberania alimentar. Revista NERA, Presidente Prudente/SP, n.16, p.22-32. 2010.

ALTIERI, M.; TOLEDO V. M. The agroecological revolution in Latin America: rescuing nature, ensuring food sovereignty and empowering peasants. The Journal of Peasant Studies, Londres, v.38, n.03, p.587-612. 2011.

ASSIS, R. L. Agricultura Orgânica e Agroecologia: Questões Conceituais e Processo de Conversão. Seropédica/RJ: Embrapa Agrobiologia, 2005. 35p.

ASSIS, R. L. Desenvolvimento rural sustentável no Brasil: perspectivas a partir da integração de ações públicas e privadas com base na agroecologia. Economia Aplicada. v. 10, n. 1, p.75-89. 2006.

BADGLEY C.; MOGHTADER J.; QUINTERO, E.; ZAKEM E.; JAHI CHAPPELL, M.; AVILÉS-VÁZQUEZ, K.; SAMULON A.; PERFECTO, I. Organic agriculture and the global food supply. Renewable Agriculture and Food Systems, 22(2), p. 86-108. 2007.

BONILLA, J. A. Fundamentos da Agricultura Ecológica: sobrevivência e qualidade de vida. São Paulo: Nobel, 1992. 260 p.

BÚRIGO, F. L. Finanças e Solidariedade: o cooperativismo de crédito rural solidário no Brasil. Estudos Sociedade e Agricultura, Rio de Janeiro, v. 2, p. 312-349. 2006.

CALLE COLLADO, A.; GALLAR, D.; CANDÓN, J. Agroecología política: la transición social hacia sistemas agroalimentarios sustentables. Revista de Economía Crítica, n. 16, p. 244-277. 2013. 
CAPORAL, F. R. Bases para uma Nova Ater Pública. Extensão Rural. Santa Maria/RS, p. 01-20. 2003.

CAPORAL, F. R.; COSTABEBER, J. A. Agroecologia e sustentabilidade Base conceptual para uma nova Extensão Rural. 2001. $<$ http://coral.ufsm.br/desenvolvimentorural/textos/13.pdf $>$. Acesso em 02 de dezembro de 2014.

CARMO, M. S. Agricultura familiar e o local na transição agroecológica. 2004. <http://www.sober.org.br/palestra/12/090417.pdf>. Acesso em 27 de julho de 2012.

CORRÊA, R. L. Dimensões de análise das redes geográficas. In_. Trajetórias Geográficas. Rio de Janeiro:Bertrand Brasil, 1997. p. 107-118.

CORRÊA, R. L. Redes geográficas: reflexões sobre um tema persistente. Cidades, São Paulo/SP, v. 9, n. 16, p. 199-218. 2012.

DIAS, L. C. Os sentidos da rede: notas para discussão. In: DIAS, L. C. e SILVEIRA, R. L. L. da (Orgs.). Redes, sociedades e territórios. Santa Cruz do Sul: Ed. UNISC, 2005. p. 11-28.

FEIDEN, A. Agroecologia: Introdução e conceitos. In: AQUINO, A. M.; ASSIS, R. L. Agroecologia: princípios e técnicas para uma agricultura orgânica sustentável. Brasília/DF: Embrapa Informação Tecnológica, 2005. p. 49-70.

FREITAS, A. F.; FREITAS, A. F. As cooperativas de crédito rural solidárias como indutoras do desenvolvimento local. Revista IDeAS, Rio de Janeiro/RJ, v. 5, n. 1. p. 160-187. 2011.

GLIESSMAN, S. R. Agroecologia - processos ecológicos em agricultura sustentável. Porto Alegre: Editora da UFRGS, 2005. 653 p.

GOMES, P. C. C. Geografia fin-de-siècle: O discurso sobre a ordem espacial do mundo e o fim das ilusões. In. CASTRO, I. E.; GOMES, P. C. C.; CORRÊA, R. L. (Orgs.). Explorações geográficas: percursos do fim do século. Rio de Janeiro: Bertrand Brasil, 1997. p.13-42.

HEROD, A. Scale: the local and the global. In: HOLLOWAY, S. L.; RICE, S. P.; VALENTINE, G. (Orgs.). Key Concepts in Geography. London: Sage, 2003, p.229-247.

HESPANHOL, R. A. M. Perspectivas da agricultura sustentável no Brasil. Confins, v.2, p. 01-15. 2008.

HOLT-GIMÉNEZ, E.; ALTIERI, M. A. Agroecología, soberanía alimentaria y la nueva Revolución Verde. Agroecología, v. 8, n. 2, p. 65-72. 2013. 
INTERNATIONAL FOUNDATION FOR ORGANIC AGRICULTURE - IFOAM. $<$ http://www.ifoam.org/>. Acesso em 10 de julho de 2014.

LATOUR, B. Reagregando o social - uma introdução à teoria do Ator-Rede. Tradução de Gilson C. Cardoso de Sousa. Salvador/BA: Edufba e Bauru/SP: Edusc, 2012. 400 p.

MAGNANTI, N. J. Circuito Sul de circulação de alimentos da Rede Ecovida de Agroecologia. Agriculturas, Rio de Janeiro/RJ, v. 5, n. 2, p. 26-29, jun. 2008.

PEREZ-CASSARINO, J.; FERREIRA, A. D. D. Agroecologia, construção social de mercados e a constituição de sistemas agroalimentares alternativos: uma leitura a partir da Rede Ecovida de Agroecologia. In: NIEDERLE, P. A.; ALMEIDA, L.; VEZZANI, F. M (Orgs.). Agroecologia: práticas, mercados e políticas para uma nova agricultura. Curitiba : Kairós, 2013. p.171-213.

PLOEG, J. van der. The drivers of change: the role of peasants in the creation of an agro-ecological agriculture. Agroecología, Universidad de Murcia, v. 6, p.47-57. 2011.

PRIMAVESI, A. Agroecologia: Ecosfera, Tecnosfera e Agricultura. São Paulo: Nobel, 1997. 199 p.

RAFFESTIN, Claude. As redes e o poder. In. poder. São Paulo: Ática, 1993, p. 200-220.

Por uma geografia do

SAHOTA, A. The Global Market for Organic Food \& Drink. In. WILLER, H.; LERNOUD, J.; KILCHER, L. (Eds.). The World of Organic Agriculture. Statistics and Emerging Trends 2013. Research Institute of Organic Agriculture/FiBL, Frick, Switzerland e International Federation of Organic Agriculture Movements/IFOAM, Bonn, Germany, 2013. p. 132-137.

SANTOS, M. A natureza do espaço: técnica e tempo, razão e emoção. 4. ed. São Paulo: Edusp, 2008. 367 p.

SCHMITT, C. J. Redes, atores e desenvolvimento rural: perspectivas na construção de uma abordagem relacional. Sociologias, Porto Alegre, ano 13, n. 27 , p. 82-112. 2011.

SEVILLA GUZMÁN, E. De la sociología rural a la agroecologia. Barcelona: Icaria. 2006.

SMITH, N. Contornos de uma Política Especializada: veículos dos sem-teto e a produção da escala geográfica. In: ARANTES, A. (Org.). Espaço da Diferença. Campinas: Papirus, 2000. p.132-159. 
SOUZA, M. L. Escala geográfica, "construção social da escala" e "política de escalas". In:_ Os conceitos fundamentais da pesquisa sócio-espacial. Rio de Janeiro: Bertrand Brasil, 2013. p.179-216.

SWYNGEDOUW, E. Globalisation or 'glocalisation'? Networks, territories and rescaling. Cambridge Review of International Affairs, v.17, n.01, p. 25-48. 2004.

WILLER, H.; LERNOUD, J. Current Statistics on Organic Agriculture Worldwide: Organic Area, Producers and Market.In. WILLER, H.; LERNOUD, J.; KILCHER, L. (Eds.).The World of Organic Agriculture. Statistics and Emerging Trends 2013. Research Institute of Organic Agriculture/FiBL, Frick, Switzerland e International Federation of Organic Agriculture Movements/IFOAM, Bonn, Germany. 2013. p. 36-128. 